Revista de la red interuniversitaria de estudios sobre las literaturas rioplatenses contemporáneas en Francia

15 | 2016

Un año. Literatura argentina 1969

\title{
Vaciamiento y repetición: figuraciones del fin de una década
}

Isabel A. Quintana

(2) OpenEdition

Journals

Edición electrónica

URL: http://journals.openedition.org/lirico/3099

DOI: 10.4000/lirico.3099

ISSN: 2262-8339

Editor

Réseau interuniversitaire d'étude des littératures contemporaines du Río de la Plata

\section{Referencia electrónica}

Isabel A. Quintana, «Vaciamiento y repetición: figuraciones del fin de una década », Cuadernos LIRICO

[En línea], 15 | 2016, Puesto en línea el 05 octubre 2016, consultado el 01 mayo 2019. URL : http:// journals.openedition.org/lirico/3099 ; DOI : 10.4000/lirico.3099

Este documento fue generado automáticamente el 1 mayo 2019.

\section{(c) $(1) \ominus$}

Cuadernos LIRICO está distribuido bajo una Licencia Creative Commons Atribución-NoComercialSinDerivar 4.0 Internacional. 


\title{
Vaciamiento y repetición: figuraciones del fin de una década
}

\author{
Isabel A. Quintana
}

\section{La retrospectiva de Roberto Aizenberg: tensiones de una época}

1 En 1969 en el Instituto Di Tella se realiza un evento que sirve de punto de partida para pensar este trabajo: una retrospectiva de la obra de Roberto Aizenberg. En el contexto del gobierno de facto de Juan Carlos Onganía y de las luchas obreras y estudiantiles, los artistas e intelectuales desarrollan en el ámbito del Di Tella (y hacia afuera) proyectos de diversas características, algunos más enrolados en la experimentación y el happening; otros generando propuestas en donde arte y política se encuentran como expresión de resistencia y acto crítico contra la represión y el autoritarismo. El caso Aizenberg, sin embargo, construye una obra en cierta forma ajena a las prácticas vanguardistas (informalismo, neofiguración, pop art), aislada pero emparentada con el surrealismo metafísico de Giorgio De Chirico. ¿Cómo entender esta producción en una década donde confluye una diversidad de actores heterogéneos y lejanos a la obra de Aizenberg? Como sabemos, el Di Tella a partir de su creación, 1958, será fundamental como referente para los que buscan participar en el ambiente de época local que remite a lo que acontece en otros circuitos culturales ya míticos: Nueva York, San Francisco, Francia. Se podría decir que en esa década acontecen diversas expresiones que dialogan, polemizan y plantean diversos posicionamientos con respecto a qué hacer con el arte.

2 Para un sector más radicalizado del Di Tella que es el que llevará adelante la exposición «Tucumán arde» en 1968 se plantea qué hacer frente al contexto político: la represión política y el desgarramiento económico bajo la dictadura de Onganía (y también cómo posicionarse con relación a la guerra de Vietnam, la revolución cubana, la derrota del mayo francés, la masacre de Tlatelolco en México). En el espíritu generalizado aparece la premisa del fin del arte (una vez más el arte se enfrenta a su muerte, gesto repetido una y 
otra vez desde finales del siglo XIX hasta nuestros días) que adquiere posiciones diferenciadas: fundición del arte en la vida cotidiana, experimentación con la tecnología masmediática, desplazamiento del ámbito del happening, la performance, despliegue de un arte corrosivo que apunta contra los gustos de la burguesía y propone una acción social concreta (hubo en el Di Tella una versión light, como expresa la propia Marta Minujín, que repele la política y se aglutina al hipismo, pero también otras prácticas que sin dejar de ser críticas al régimen son aceptadas por un público más masivo, como es el caso de Nacha Guevara).

En el 69 se realizan diversas actividades en el Instituto ya en el borde de su ciclo, meses después la dictadura ordenará su cierre definitivo (su vaciamiento). Como declara Roberto Jacoby, después de la experiencia de «Tucumán arde» (exposición que se exhibe solamente dos semanas en Rosario y apenas algunas horas en Buenos Aires en una situación de semiclandestinidad, mostrando las condiciones paupérrimas de la población a causa del vaciamiento de los ingenios azucareros) se produce un quiebre en la vida de sus actores que consiste en una toma de posición: o bien, pasar a la clandestinidad ante la amenaza de la dictadura y encontrar otros caminos para asumir cierto compromiso con lo social (Roberto Jacoby, actor fundamental en la vida del Di Tella, decide entonces estudiar sociología), o elegir el camino del exilio ${ }^{1}$. Esta bisagra, punto de quiebre en la vida cultural de Buenos Aires, nos permite leer este año como condensación y expansión de lo que fue evidentemente una época: los años 60 . Nuestra empresa es mínima, apenas una pequeña intervención en medio de la prolífica bibliografía que se ha escrito sobre esa década, pienso especialmente en el libro de Oscar Terán: Nuestros años sesentas.

Ese año, entonces, se exhibe en el Centro de Artes visuales del Di Tella una retrospectiva de la obra de Aizenberg. Ésta será una forma de ingresar, una entrada, un punto de partida o también una excusa para luego analizar más en profundidad la novela de Saer y el film de Favio. En La obra de Aizenberg leemos procedimientos que en materialidades diferentes se expresarán en Cicatrices (1969) y en El dependiente (1969). Aunque Aizenberg ha participado en diversos momentos de las actividades del Di Tella su obra resulta particularmente interesante para pensar lo que se puede denominar una práctica del vaciamiento. No se trata de afirmar que su propuesta responda a la idea del fin del arte, sino de decir que ella plantea una estética que depura el espacio icónico, especialmente el antropomórfico y que por esa vía confronta toda idea del realismo (como simple reproducción de mundo, como unidad y coherencia, como figuración del hombre y su entorno) para drenar a través de la repetición de determinados escenarios significantes de angustia. En ese sentido, como ocurre con la obra de Saer y Favio, estaríamos ante la afirmación plena del arte, pero en la variante vanguardista que se compone de dos movimientos: vaciar el espacio-texto de toda forma familiar para devolver una figuración extrañada del mundo. En Aizenberg, el espacio se ha vaciado de la presencia del hombre cuestión que resulta además muy impactante si pensamos en la irrupción de manifestaciones colectivas políticas y artísticas hasta llegar al Cordobazo en el 69, y ya a partir de los 70 la plena presencia de las grandes movilizaciones sindicales y la irrupción de Montoneros y otras organizaciones armadas (la proscripción de Perón tiene un peso innegable en los films de Favio (su trilogía) y de alguna manera en la novela de Saer). 


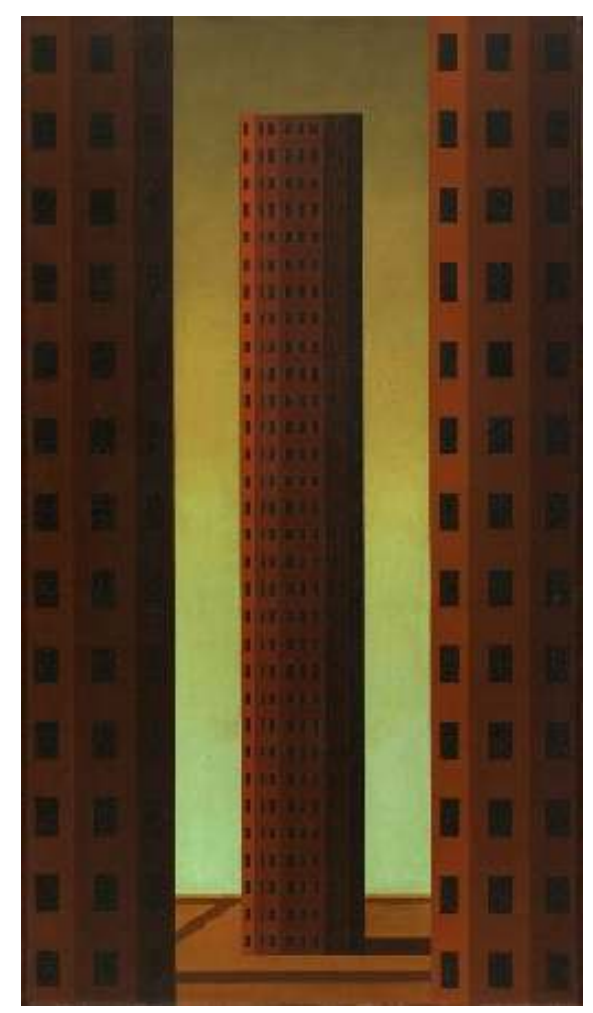

ROBerto AIZenberg "Pintura", 1965. Óleo sobre tela, 80 × 45 cm

5 Aizenberg transita esos años a partir de un abordaje del borramiento humano lo cual no significa su negación, por el contrario, la presencia de grandes edificios deshabitados en espacios vacíos supone justamente que fueron construidos por los hombres. En realidad, existe un abordaje de lo humano a partir de su no presencia o su aparición ominosa (como en la serie "padre e hijo») en espacios también vaciados y, en sus últimas obras, a partir de un trabajo de disección de lo icónico humano que alude nuevamente a su ausencia y a la rememoración de su existencia. Respecto a este proceso de desactivación de la maquinaria antropológica (lo humano como sujeto pleno y dador de sentido) Saer y Favio construyen singularidades ensimismadas y atrapadas en su propio vacío. Los tres realizan una intervención que es excéntrica con respecto a las corrientes o grupos nucleados en torno a una estética o programa definido. En Aizenberg este vaciamiento se presenta en la configuración de moles, muros que remiten a cierto anacronismo, un juego surrealista en donde ingresa la pesadilla, el grito mudo: el mundo sigue en pie pero sin la presencia humana y en el presente puro confluyen imágenes que no vienen exactamente del pasado sino que aluden a cierto imaginario de la cultura hecha de un archivo iconográfico. Cuando aparece un hombre lo hace de espaldas y acompañado por un niño en una relación desproporcionada entre la pequeñez de ambos y la inmensidad amenazante del mundo: esta imagen se repetirá una y otra vez en diferentes lienzos (una serie que comenzó en 1956). Qué miran ese hombre y ese niño en un paisaje despojado de plenitud, un paisaje de gran inmensidad donde no hay presencia de otras vidas, poblado de colores ocres y oscuros («Padre e hijo contemplando la sombra de un día», 1962). Como si fuera una condensación premonitoria de la posterior desaparición de sus hijos que más tarde volverá a replicar en la construcción de una escultura de grandes dimensiones en la Costanera Norte (luego Parque de la Memoria), donde padre e hijos (porque ahora se agregan otros, recordemos aquí la desaparición de los sobrinos del artista que fueron adoptados por él) dan la espalda a la avenida y miran ahora de frente al Río de La Plata (la 
escultura se rotula de manera sugestiva: «Sin título»). Frente a un río que fue escenario de los vuelos de la muerte durante la dictadura, la escultura de Aizenberg hurga en su propio imaginario y actualiza la serie padre/hijo. La inscripción es aquí paradójica porque el paisaje sigue siendo tan desolado como el de sus cuadros pero, a la vez, resignifica un espacio. El vaciamiento es complejo porque si bien la matriz paterno-filial se dramatiza ante la sugerente presencia del río y entonces se exacerba la inmensidad abierta de sus imágenes anteriores, a su vez interviene sobre ese espacio sin por eso cerrarlo: lo que se dibuja ahora es ese resto que impedirá eternamente toda clausura.

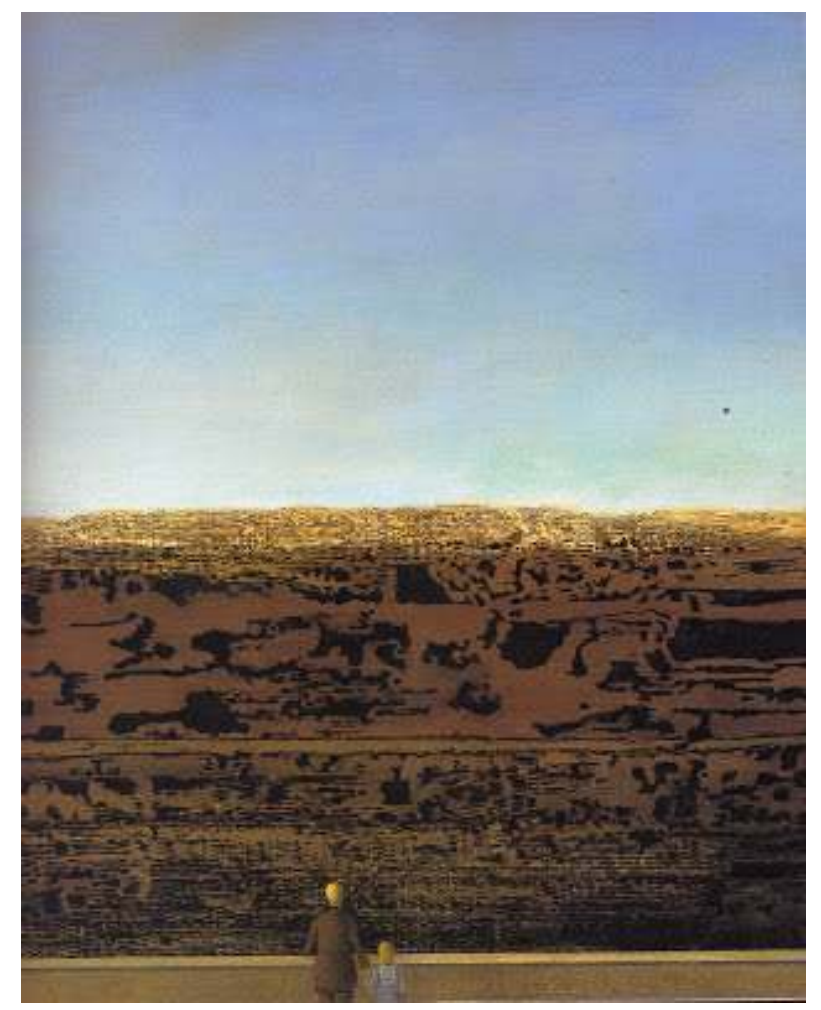

Roberto Aizenberg, "Padre e hijo contemplando la sombra de un día", 1962. Óleo 45 ×35cm

Como plantea Aldo Pellegrini en la reseña que realiza para la retrospectiva del Di Tella en el 69, tres son los elementos fundamentales que componen los cuadros de Aizenberg: espacio, luz y arquitectura ${ }^{2}$. La luz define la dirección de la mirada, los momentos de tensión, el derrumbe, la amenaza (como en «El incendio en el colegio jasidista de Minsk 1713», 1952). Pero el vaciamiento no supone la interrupción del acontecer: es lo que queda del mundo y lo que se anuncia como eclosión, la suspensión del sentido, el no saber, la incertidumbre. Por lo tanto, el tiempo más que suspendido se encuentra extendido, hay un agujero en la conciencia del ser que es lo que perdura de la presencia humana y por él se filtran las imágenes de sus sueños, el fuego como residuo onírico del colegio jasídico en llamas (¿referencias a un progrom?, nada de eso explicita su propio autor como hecho puntual, aunque su alusión es más que sugerente). Y lo que le da forma a la imagen plasmada en la tela es del orden de la repetición: geometrías abstractas y poliédricas, edificios, torres en las que reaparecen los ventanales en serie del mismo modo que los muros cuyas manchas se suceden también de modo continuado. Estas composiciones insistentes en su arquitectura y congruencia provienen de un momento anterior: el azar del que se nutre el artista, una mancha que luego se trastoca en una imagen definida y repetida. Esa pulsión por la repetición es la escena en que se dan cita 
los fantasmas que deben procesarse a fuerza de aparecer y nombrarse: «Aizenberg incorpora elementos que están más allá de la pintura» (Pellegrini 1969). Y cuando finalmente aparezcan en sus dibujos figuras que remiten a lo humano estarán vaciadas de todo realismo: fantoches, robots, figuras geométricas y fragmentadas (como en Picasso) pueblan los espacios y aluden nuevamente a cierta dimensión de ensoñación. Esa partición de la figura humana replantea el nexo entre espacio y tiempo, pero ahora en relación a la composición y descomposición de un cuerpo, la percepción sobre ese proceso desde la mirada del otro, la incertidumbre de la imagen: la desolación es el gran tema que marca su obra (como la soledad marca la del primer Favio y también Cicatrices de Saer) ${ }^{3}$.

7 Leo esta exhibición de Aizenberg en el Di Tella como un momento de quiebre después de los ruidosos años 60 , no como una clausura sino como forma enigmática, como el silencio previo al gran estallido de los 70 (no olvidemos que en esos años ya ha comenzado a plantearse una épica de la presencia junto a la de la resistencia; pienso, por ejemplo, en $L a$ hora de los hornos de Pinos Solanas, 1968).

\section{Diferencia y repetición: formas del vaciamiento en Cicatrices}

8 En 1968 Deleuze publica Diferencia y repetición. Contra la idea de representación platónica Deleuze intenta abrir una grieta que no oponga razón a no razón sino una lógica diferente. Se trata de pensar lo diverso en el interior del sistema descentrándolo. Para ello considera la diferencia y la repetición como los signos que ocupan el lugar de la identidad y la contradicción. La diferencia es lo singular, lo irreductible y es precisamente la repetición la que produce esas diferencias. La repetición «no es añadir una segunda y tercera vez a la primera vez a la enésima potencia, lo que en justicia vale es este $n$ veces como potencia de una sola vez, sin que haya necesidad de pasar por una segunda o una tercera vez» (1972: 50-54). Siguiendo con su antiplatonismo, en Lógica del sentido, publicada en 1969, Deleuze propone contraponer al mundo de la representación el de la superficie con sus simulacros, los fantasmas y los objetos incorpóreos ${ }^{4}$. De este modo Deleuze (2002) va desarrollando una idea de la imagen ligada a la sensación que, a partir de los cuadros de Bacon, la concibe como el inicio de un trazo que puede no dibujar un contorno definido. La imagen sería lo que está entre la cosa y la representación. De allí que la idea de intervalo junto a la del movimiento limitado adquiera especial relevancia (y que nos será fundamental para pensar la escritura de Saer):
Los niveles de sensación serían como detenciones o instantáneas de movimiento, que volverían a componer el movimiento sintéticamente, en su continuidad, su velocidad y su violencia: como el cubismo sintético, o el futurismo, el $\mathrm{Nu}$ de Duchamp. [...] El redondel o el paralelepípedo, el aislante de la Figura, se convierten en motores, y Bacon no renuncia al proyecto, que una escultura móvil realizaría más fácilmente: que el contorno o la peana puedan desplazarse a lo largo del armazón, de tal manera que la Figura dé una pequeña vuelta cotidiana. [...] y es una pequeña vuelta a la manera de los paseos de los personajes de Beckett, que se desplazan, también ellos, dando tumbos sin dejar su redondel o su paralelepípedo (Deleuze 2002: 47).

Como dice Oubiña, la escritura de Saer, en cuyo origen está la relación con el cine, interrumpe la continuidad de las imágenes (2011). Saer fractura el tiempo, lo detiene y de ese modo la literatura se espacializa frente a la parálisis narrativa, pero a diferencia del 
Bacon de Delueze, lo que queda es ese despedazamiento: no hay posibilidad de una recomposición (un movimiento sintético):

Lo que lo obsesiona [al narrador de La mayor] hasta la parodia es la búsqueda de alguna finalidad en los actos, alguna conexión que llegue de uno a otro, que revele alguna estructura subyacente a esa realidad informe en la que se mueve como hundiéndose en el lodo. Obediente a ese mandato, inmoviliza y aísla uno tras otro diferentes detalles de ese flujo, los estudia bajo el microscopio de su percepción [...], las cosas se ven desmenuzadas una y otra vez hasta desintegrarse y quedar reducidas a la insignificancia más absoluta (Oubiña: 83- 84).

10 Esa discontinuidad que Deleuze (2014) ha leído en cierta vertiente del cine desde una perspectiva bergsoniana plantea otra mirada del mundo. Digamos que no hay realismo porque no hay representación del mundo, sino que el mundo se ha constituido en la experiencia de una fragmentación incluso más cercana a lo real. En ese sentido las imágenes de Aizenberg también suponen un trabajo de detención (una detención extendida): vaciar al mundo de la representación realista, y detenerse en el espacio de la ausencia que está amenazado por la llegada del acontecimiento. Siguiendo a Deleuze, repetir es hacer emerger esos objetos fantasmáticos, singulares, diferentes cada vez. Abrir una brecha en donde toda identidad está amenazada. Por eso, los textos de Saer producen ese intervalo al mismo tiempo que opera la repetición: una misma historia contada una y otra vez desde diferentes perspectivas pero que introducen una diferencia en su singularidad: el detalle que parece perder o no poder percibir Leto en el relato que el Matemático y Tomatis comentan en Glosa, o las siete variantes de la misma historia en Nadie nada nunca; pero también una misma acción repetida (comer, vestirse, manejar, mirar determinada imagen, caminar, jugar al punto y banca, traducir un texto como sucede en Cicatrices) que son las que fragmentan y al mismo tiempo les dan cierta cohesión a los personajes. Frente a la debacle total, Sergio Escalante sigue jugando al punto y banca en Cicatrices, y Tomatis en Lo imborrable mantiene una rutina elemental para contrarrestar el desastre.

11 Leemos en Cicatrices todas las narraciones de Saer que vendrán: la circularidad de un relato que no avanza porque no hay en verdad nada que contar se sostiene sobre un centro vacío sobre el que giran encapsulados los personajes en un puro presente. Moviéndose en una órbita que los aparta del resto (como en Los planetas de Sergio Chejfec), vuelven sobre sus propios pasos y hábitos (los mismos recorridos por la avenida San Martín, los mismos edificios que los circundan) y por leves instantes sus constelaciones se cruzan. Una topografía esencial que define además una zona, un territorio (y que ingresa en una tradición que va desde Faulkner a Onetti). En Zona Saer Sarlo (2016) ha encargado organizar el dibujo de esa deriva en un plano a dos especialistas. Allí se observan las caminatas obsesivas en sus desvíos y desplazamientos, variantes de la repetición. «Sobre la topografía real trabaja la imaginación narrativa. [...]. Introduce desvíos, pequeñas trampas topográficas, fabulaciones en miniatura, sin consecuencia. [...]. Sus lugares se repiten como solo puede repetirse la literatura, y producen efecto de verdad» (116- 117).

12 Como dijimos, la escritura bordea un centro vacío, un resto que impide el cierre de la circularidad textual y al que los personajes se acercan desde su respectiva mónada. Como sabemos, se trata de la historia de un sindicalista que asesina a su esposa un $1^{\circ}$ de mayo y luego se suicida tirándose desde la ventana del edificio de los Tribunales cuando el juez Garay le está tomando declaración. El texto se divide en cuatro partes tituladas por la serie de meses, que se va contrayendo hasta anclar en mayo («febrero, marzo, abril, mayo, 
junio»; «marzo, abril, mayo»; «abril mayo»; «mayo»). Desde el comienzo hasta el final de la novela se instala la historia de Fiore, y lentamente la escritura va bordeando el relato del suicidio hasta enfocarse en el sindicalista, comprimiendo el tiempo en un mes: mayo. En realidad, en una porción de ese mes, en dos días $1^{\circ}$ y 2 de mayo -en los que suceden el asesinato y después el suicidio. Como círculos que van acercándose hasta el más pequeño, pero que en realidad es el centro, pura cáscara, vacío, sin sentido. Como dice Ángel:

Cuando un tipo se estrella así contra una ventana y después vuela por el aire y va a dar contra el suelo desde el tercer piso, no se rompe nada [....]; nada, como no sea una cáscara vacía. Porque el tipo ya está hecho pedazos desde antes de tirar lo que queda de él, la cáscara vacía (81).

13 En cada una de esos capítulos el protagonista encarna la voz narrativa: Ángel Leto, Sergio Escalante, Ernesto López Garay, Luis Fiore. Las voces modulan la experiencia y en la letanía narrativa reformulan una y otra vez el espacio de la repetición a través de sus acciones que tienen un carácter compulsivo: leer, jugar, traducir, andar en auto, mirar por la ventana, matar. En esa configuración hay elementos que son fundamentales para que tales acciones y sus intervalos se produzcan: el juego de luz y sombras que definen las siluetas, la ciudad con sus edificios (el del diario La Región en el que trabajan Tomatis y Leto, los Tribunales en donde se desempeña como juez Garay), los entornos (paisaje, mesa de juego, los interiores de las casas) y los encuadres: puertas y ventanas. La iluminación (los conos de luz de las mesas de juego) y el frame confluyen en el procedimiento del corte, el aislamiento. La mirada enmarcada aparece nítidamente en el primer capítulo cuando Tomatis inesperadamente deja de escribir a máquina, se para y mira a través de la ventana, se repite cuando la sirvienta de Escalante realiza cotidianamente el mismo gesto de mirar el suelo lleno de manchas del patio a través de la puerta o ventana de la cocina. Y se agudiza con Garay, quien no puede dejar de mirar desde la ventana de su casa el espectáculo de los gorilas (así llama a la masa anónima de gente que se reproduce en sus sueños). La nada que mira Tomatis, las manchas sobre la que obstinadamente ha dado batalla Delicia para hacerlas desaparecer, la presencia de los gorilas, la lluvia constante y el propio edificio de Tribunales que también mira Garay a través de la ventanilla de su auto, se perciben por medio de ese marco como un tamiz que establece una distancia, produce un detenimiento, un fotograma de las imágenes informes o borrosas que provienen del exterior: «Saer presenta el relato como la visión de una cámara que se acerca o aleja, que modula los detenimientos, ralenta el tiempo narrativo, muestra cuadro a cuadro o utiliza un lente de aproximación [...], geometría temporal que trasciende el plano» (Figliola-Yoel 2011: 64).

Como en Aizenberg, la inminencia de un acontecimiento frente al achatamiento del mundo se va dibujando lentamente, en ese ralentando y fragmentación de las secuencias, en cada apuesta desesperada de Escalante (cada manojo de cartas vueltas a mezclar), en los intervalos que dejan ingresar el silencio, en las miradas de los personajes, aislados, solitarios que observan un paisaje nada nítido, a medio borrar, como padre e hijo en las pinturas de Aizenberg, solo que aquí Leto observa a Tomatis mirar, Escalante hace lo mismo con Delicia y nosotros, a su vez, los vemos mirarse unos a otros de espaldas. Como también lo vemos a López Garay mirar un paisaje amenazante (los gorilas reaparecen reiteradamente en sus sueños como la horda primitiva, una escena originaria donde la sexualidad acontece como práctica exacerbada que se repite y anuncia, tal vez, la novela El entenado). Y la ventana que en la oficina de Tribunales mira Fiore al sentarse para declarar ante Garay y que minutos después estalla tras su caída; emergencia del 
acontecimiento que nos hace volver a releer la novela a partir del suicidio del dirigente sindical Fiore, días después del $1^{\circ}$ de mayo.

Justicia y animalidad bordean ese hueco, la cáscara vacía que será el cuerpo de Fiore al caer por la ventana: un cuerpo ya previamente vaciado (como las figuras de Bacon) y que revienta contra el asfalto: fragmentos de un cuerpo, insisto, que nos hace volver a releer la novela y a editar un contexto (los pedazos de una historia, lo que quedó tras el peronismo). Mientras, Sergio Escalante, también abogado y peronista, ha dejado de representar a los trabajadores para dedicarse a desafiar al azar («antes defendías a los trabajadores» (155) le dice el Negro, antiguo compañero, cuando lo va a visitar para que defienda a Fiore). López Garay, el juez, administra la justica de forma inquietante y pone en entredicho su fundamentación (no se es mejor por estar fuera o dentro de la cárcel, le dice a Leto). Una justicia degradada que tiene sus propios fantasmas que se presentan como lo irreductible: Fiore, la horda de gorilas, el hombre despojado de sus atributos, la evidencia de su cercana contigüidad con lo animal; es decir lo heterogéneo de la ley, no lo que está expulsado de ella sino la diferencia que la habita en su interior. Por eso la repetición en López Garay pertenece al orden de lo inasimilable (poblaciones de gorilas de las que huye permanentemente, la lluvia que lo acosa en sus travesías), y para drenarlo desplaza su rutina al ámbito de lo imaginario: la traducción interminable y diferida de $\mathrm{El}$ retrato de Dorian Gray. También de forma compulsiva busca en el diccionario posibles significaciones para una palabra y, en ocasiones, la traducción de un párrafo coincide con otra ya publicada, contraborgianamente no puede escapar de la repetición y las derivas del lenguaje no son infinitas, al menos para este juez decadente. La literatura tampoco salva, por eso Saer arremete tan drásticamente contra todo vestigio del realismo en el interior de la novela a través de las discusiones que entablan sus personajes, y en los procedimientos que aniquilan toda idea de verosímil realista. Finalmente, Ángel, quien encarna los atributos de Tonio Kröger, libro que le regala Tomatis, comprende de forma brutal (la traición de Tomatis, el suicidio de Fiore) la imposibilidad de unir arte y vida para redimir la humanidad.

16 Saer también introduce materiales bajos, el mundo de los comics con los que el exabogado Escalante, cuando no juega, construye divertidos ensayos a modo de collage mezclando la figura de Superman con la filosofía contemporánea. Si la literatura no salva (no tendría por qué hacerlo), tampoco lo hace la justicia. La mole helada del edificio de Tribunales se eleva ante la mirada de los personajes que recorren los mismos circuitos: una masa enorme poblada de gorilas en la que Garay intenta permanecer el menor tiempo posible. El edificio de la justicia acosado por una lluvia que no cesa y que López Garay no deja de describir (su grosor, color, iluminación) ocupa la centralidad de la topografía pero va perdiendo nitidez, envuelto en la masa de lluvia. Fálico, amenazante y, sin embargo a medio borrar. Perdiendo sus contornos, convirtiéndose también en una cáscara vacía.

\section{Circularidad y asfixia: formas de la desolación en EI dependiente}

17 La del 60 es una década en donde está todo expuesto y también reprimido: la revolución, las masas, la crisis del arte y al mismo tiempo su furor. La idea de un arte para el pueblo impregna la época y se extenderá en la siguiente. En el caso de Leonardo Favio, lo nacional y popular es casi una declaración de principios del propio director, de la que también se ha nutrido la crítica. Sin embargo, ¿qué supone la idea de un cine que abreva 
en cierto costumbrismo local? En realidad, Favio mantiene una relación tensa con las costumbres y moral pueblerinas típicas de su trilogía: Crónica de un niño solo (1965), El romance del Aniceto y la Francisca (1967) y El dependiente (1969). Y aunque el cine de izquierda de los 60 estaba sumergido en la experimentación influenciada por las modas europeas, mientras otros postulaban una estética militante latinoamericana, Favio también puede incluirse en un cine que a través de otros recorridos (Torres Nilsson es para él el punto de inflexión del cine argentino que retorna al campo de lo nacional y popular) exhibe una provocadora concepción fílmica. Su cine descoloca la vertiente realista a través de la exasperación de los comportamientos sociales, en la que realismo y experimentación atraviesan lo popular. En El dependiente, como ha dicho el propio Favio, ya se condensa una estética que desplegará en toda su obra: el encuadre está fundamentalmente puesto en la mirada y el rostro de sus personajes. Como en las novelas de Saer, la cuestión de lugar delimita también una forma resistente de narrar junto a la elección de los personajes (en Cicatrices, la figura del sindicalista es lo que aparece como lo otro, en un mundo donde Tomatis, Garay y Escalante -ilustrados y nihilistas- confrontan toda certeza ideológica y literaria). Como Favio, Saer se nutre de ciertas corrientes que vienen de Europa pero su trayectoria es inversa. Quiero decir: si El dependiente se centra fundamentalmente en una historia pueblerina asfixiante, circular y alucinada, Saer, en Cicatrices, también escribe la circularidad anodina de cada uno de los personajes mientras el peronismo como espectro agudiza un cierto desapego y abandono en los antiguos compañeros.

En los primeros films de Favio, la ausencia de la figura mítica de Perón, la desolación (una desolación que determina a los personajes y que es constitutiva da cada uno de ellos) y la destitución de la idea de justicia ante la presencia de vidas expuestas a su mera repetición puede leerse junto a su propio repliegue (solitario, casi apartado del resto de los debates contemporáneos, Favio hace un cine de vanguardia). Este vaciamiento se inscribe en el terreno de la proscripción del líder y adquiere en la ficción la imagen del abandono que tan claramente encarna Polín, el niño de Crónica de un niño solo. En este film «se cruzan los lenguajes formales de la vanguardia, el impulso documental y la perspectiva melancólica del peronismo de la resistencia que percibe el presente como ruina y el futuro deseable como restauración de una pérdida» (Nouzeilles 2010: 120). Ese abandono e incomunicación, plantean Aguilar y Oubiña, impregnan toda la imagen, se trata de un estado existencial que repercute en los propios espectadores (1993: 61), pero que en ningún momento permite la identificación. Por el contrario, el desarrollo del drama está impregnado de una parálisis afectiva por parte de los personajes, que se mueven rutinariamente en un ambiente asfixiante de represión moral, avaricia e introspección. La delimitación espacial: el pueblo, que se ha reducido a un espacio mínimo: el que va de la esquina de la ferretería en donde trabaja Fernández, el dependiente, a la casa de la señorita Plasini, Graciela Borges, a unos poquísimos metros. Y dentro de la ferretería el espacio en el que se mueve Fernández y el viejo es un mínimo subsuelo donde comen y duermen.

Desde Crónica hasta El dependiente, Favio construye escenarios al borde de la abstracción expresionista, poblada de geometrías, recortes, en una figuración precisa, calculada, medida, administrando una suerte de economía de las imágenes y de la lengua. Algunos personajes apenas hablan o solo pueden repetir frases hechas, Fernández no tiene un lenguaje para expresar lo que siente por la muchacha y dice «es el amor» cuando en realidad quiere decir que la ama. No hay prácticamente diálogos, lo que hay son formas 
mínimas del decir y largos silencios. Todo adquiere la figura de un gran artificio, la repetición mecánica de los rituales, las formas extrañas de expresarse que parecen subrayar una cierta teatralidad, a lo Bresson: las «voces blancas [...]. Cada uno dice su parlamento como si repitiera exagerada y a la vez desapasionadamente un texto aprendido de memoria» (Aguilar y Oubiña: 72). El espacio aplana el tiempo de las historias que son relatos casi inexistentes, en atmósferas sumamente concentradas: pobreza, escasez de objetos, austeridad minimalista, voces agónicas o murmurantes, torpeza corporal.

El dependiente Fernández (Walter Vidarte) concentra muchas de estas características pero en este film se enrarece la circularidad desesperante ya presente en Crónica... (el niño huye del reformatorio, vuelve a su villa miseria y nuevamente es apresado por un policía que lo devolverá a la institución). En toda la película el clima es el del retiro del Estado paternalista frente a la violencia correccional. El efecto es de círculos que se van cerrando y ensimismando, como en Saer cada personaje pertenece a una esfera propia, de viciada circularidad (usan la misma ropa, se sientan en la misma posición, se mueven con dificultad). Replegado sobre sí mismo constituye la presencia enigmática para el otro. Y, a su vez, componen un cuadro repetido en que la aproximación es rigurosamente medida, tallada en sus bordes (luz y sombra enmarcan los encuentros de la pareja en la calle o en el patio de la casa) atravesada por la rigurosa observación que mantienen entre ellos. Nadie puede desplazarse libremente sin que la mirada del otro lo delimite. La mirada ejerce su tiranía y determina relaciones de subordinación. Los círculos se tocan, como en Cicatrices, y comienzan a prosperar en una constelación siempre al borde del estallido.

La pausa también aparece como recurso entre la espera de la llegada del otro, o la espera de que el otro diga algo, mínimo, pero que mantenga latente el circuito fáctico de una comunicación que nunca es tal, porque todo es una puesta en escena, una hipócrita escena en donde cada uno esconde sus verdaderos deseos (Fernández: que muera Don Vila y quedarse con la ferretería; la señorita Plasini: casarse con Martínez para huir de una madre aborrecible; la madre: garantizar el matrimonio de la hija). La película en realidad es la larga espera de la muerte del dueño de la ferretería, Don Vila (Fernando Iglesias) y es ese miserable horizonte de expectativas el que provoca el acercamiento de Fernández y la muchacha. Como en el Romance del Aniceto y la Francisca, el afuera es el espacio donde acontece el mundo pero generalmente envuelto en un insoportable silencio que apenas se suspende ante episodios de presencia colectiva de carácter costumbrista: la riña de gallos (en el Romance) o el despliegue de una banda militar (en El dependiente). No hay comunidad de afectos, y los que apenas emergen se encuentran determinados por una economía mínima, precaria, amenazada por derruirse. Es un mundo que se sostiene por los gestos repetidos que reprimen todo desborde o exceso. Pero en esa letanía hay irrupciones delirantes que desacomodan el cuadro, los personajes se fisuran brevemente, pierden el control, la autorrepresión insistentemente sostenida (por el qué dirán): el gato vapuleado por la madre, el grito de la señorita Plasini en la puerta de su casa que es una verdadera descarga sexual, la eclosión de un orgasmo, la mano de Fernández en la pierna de su novia en el auto funerario de regreso del entierro del ferretero. Estallidos que luego se apagan y nuevamente todo retorna a la misma circularidad. Pero Favio introduce otros elementos que se suman a la perturbadora mismidad, porque en la repetición de una represión sostenida la atmósfera es la de una tranquilidad inquietante. Nuevamente apelando a recursos del imaginario cultural de la época, Favio convierte la casa pueblerina de las Plasini en un recinto poblado de ceremonias espiritistas, casi al borde de lo fantástico o de 
un gótico bizarro pueblerino. En el patio, bajo la claridad de la noche donde se reúne todas las noches la pareja, la iglesia que linda con la casa de las mujeres irradia otras presencias que la vieja administra para su economía hogareña (es la casera del lugar). Dos elementos confluyen para dislocar y al mismo tiempo confirmar la circularidad familiar: la presencia monstruosa del hermano al que tienen escondido en algún lugar de la casa y en un momento se escapa, y la foto del padre de la muchacha que tiene el mismo rostro de su pretendiente. La sorpresa de Fernández al ver en la cara del suegro muerto su propia cara no alcanza para escapar del círculo, más bien se repliega a lo que ya entonces sabrá que será su destino, el de encarar los atributos del pater familias. Desde el punto de vista espacial, el circuito es tan mínimo que el recorrido de la casa familiar a la nueva casa es apenas de unos pocos metros. Tras la muerte del viejo Vidal, el casamiento de los jóvenes y su vida ya en la ferretería, el film cambia su enfoque y repite los primeros planos del comienzo, solo que ahora el viejo ferretero está encarnado en la figura de la joven Plasini. La misma rutina, la misma economía austera, el mismo maltrato hacia Fernández. La esposa asume la figura del ferretero exacerbando su avaricia y crueldad. Fernández continúa siendo un dependiente, jamás logrará salir de esa subordinación que al mismo tiempo determina su vínculo con la esposa (amo y esclavo se necesitan). Para romper el círculo sería necesario acabar con el escenario mismo de la repetición.

La escena final es la misma que el dependiente mantenía cotidianamente con el viejo: un almuerzo frugal en que la Plasini, igual de despótica, le ordena colocar los ingredientes. Allí en ese sótano miserable Fernández revuelve lentamente la olla cuando descubre el arsénico y coloca una pizca en la sopa. La mirada final de Fernández es una mirada de goce perverso: finalmente se romperá el cerco.

En este film Favio ha ido cerrando la circularidad iniciada en Crónica. Ha depurado el ambiente hasta convertirlo en un artificio sin elementos fuera de campo para concentrar en dos escenas: la que acontece en el patio de las Plasini y la que ocurre en la ferretería, la vacuidad de los personajes. Se ha clausurado un ciclo en donde el silencio final que acontecerá tras la muerte de los personajes supone un corte en esta secuencia. Una suspensión también en la carrera cinematográfica de Favio. Tras este quiebre, el silencio, la circularidad, la experimentación formal se transformará años después en un proyecto inspirado en los mitos populares. Pero todavía en el filo del cambio de década el cine de Favio, como las imágenes de Aizenberg, dibujan un territorio incierto.

\section{Singularidades y coincidencias}

Si como planteamos al comienzo de este trabajo, el 69 puede pensarse como una condensación y expansión de los 60 en donde proliferan apuestas artísticas heterogéneas e incluso planteando tensiones en torno a su relación con una sociedad convulsionada políticamente, el corte de lecturas que aquí proponemos supone una revisión de dichas prácticas desde un lugar que es inherente pero a la vez de ubicación compleja respecto a las vanguardias. Consideramos que estas obras se presentan como una variación en donde sigue vigente la pregunta: qué es el arte o también lo reafirman en su trabajo pero a partir del desmontaje de figuras, formas y textos. $Y$ en ese ejercicio nos devuelven un mundo conocido pero al mismo tiempo perturbador, siempre en el límite de la abyección. Frente a un arte y a una militancia de los 60 que se caracteriza por ocupar espacios, intervenir en la escena pública, y conjugar un lenguaje plagado de ideologemas, las obras analizadas aquí trabajan en el límite formal, producen una exforma que se repliega en una 
suspensión interrumpida. Aizenberg, Saer y Favio ensayan diversas prácticas de vaciamiento que generan su propia singularidad. No es un detalle menor pensar que frente al imperio del exceso, lo performático, el happening, el arte pop, pero también el arte comprometido y experimental, estos creadores producen su obra de manera solitaria aunque sin dejar de nutrirse de ciertas tendencias vanguardistas.

Así, podemos delimitar tres procedimientos que procesan los materiales heredados llevándolos al borde o a un precipicio del que no será fácil retornar. La suspensión de sentido impregna las tres poéticas, pero cada uno trabaja con un imaginario que los diferencia definitivamente el uno del otro. En Aizenberg asistimos al recurso del anacronismo en donde el vaciamiento del mundo se da por la paradoja antropológica de la ausencia-presencia de lo viviente frente a gigantes conglomerados arquitectónicos o paisajes oscuros en donde asoman los cuerpos diminutos. La apuesta de Saer es la de confrontarse a ese núcleo vacío que implica no solo una suspensión de toda certeza sino también la puesta en práctica de una escritura repetitiva que transita en su diferencia por cortes e interrupciones. Lo real es lo que siempre asoma y amenaza pero es aquello a lo que no se puede acceder, y aunque insistentemente los personajes se resguardan de su acecho enmarcando su mirada, el horror es justamente su vacío: no hay nada, nadie, nunca.

Descomponer un mundo, fragmentarlo, suspenderlo en sus ruinas y alimentarse de sus restos es lo que Favio realiza en su cine. Destilar gota a gota la soledad de sus personajes, desgranar el universo de poses y gestos repetidos hasta el cansancio, vaciarlo de su pura circularidad hasta que se produce el corte. Descomponer ese mundo para volver a componer su artificio, saturarlo de una continuidad pueblerina en el que se mueven los personajes mecánicamente. También aquí el sentido está aplazado o suspendido. La Historia se ha borrado y en un estado de orfandad quedan boyando los personajes de Favio. El vaciamiento se produce también por capas de aislamiento, por la ajenidad de los personajes con respecto a la trama histórica. A fines de los 60 , esta decisión de Favio, sin embargo, no puede dejarse de leer como un gesto claramente político y una provocación. En los 70 su cine cambiará definitivamente de rumbo.

\section{BIBLIOGRAFÍA}

Deleuze, Gilles, Cine I. Bergson y las imágenes, Buenos Aires: Cactus, 2014.

Diferencia y repetición, Barcelona: Anagrama, 1972.

Francis Bacon. Lógica de la sensación, Madrid: Arena Libros, 2002.

Logique du sens, París: Les Editions de Minuit, 1962.

Figliola, Alejandra y Gerardo Yoel, En fiebre y geometría. Puig, Saer y Mercado, entre literatura y cine, Buenos Aires: Imago Mundi - Universidad Nacional de General Sarmiento, 2011. 
Longoni, Ana (comp.), El deseo nace del derrumbe. Roberto Jacoby: acciones, conceptos, escritos, Barcelona: La central, Adriana Hidalgo, Museo Nacional Centro de Arte Reina Sofía, Red conceptualismos del Sur, 2011.

Nouzeilles, Gabriela, «El niño proletario: infancia y peronismo», Soria, Claudia; Cortés Rocca, Paola y Dielke, Edgardo (comps.), Políticas del sentimiento, Buenos Aires: Prometeo, 2010.

Oubiña David y Gonzalo Aguilar. De cómo el cine de Leonardo Favio contó el dolor y el amor de su gente, emocionó al cariñoso público, trazó nuevos rumbos para entender la imagen y otras reflexiones. Buenos Aires: Nuevo extremo, 1993.

Oubiña, David, El silencio y sus bordes: modos de lo extremo en la literatura y el cine, Buenos Aires, FCE, 2011.

Pellegrini, Aldo, «[Ninguna de las artes...]», Aizenberg: obras 1947/1968. Exh. cat., Buenos Aires: Centro de Artes Visuales del Instituto Torcuato Di Tella, 1969. En línea: icaadocs.mfah.org/icaadocs/ ELARCHIVO/.../tabid/99/.../Default.aspx. Consulta: 08/06/2016.

Rodríguez, María del Carmen, «Imágenes en el tiempo en el cine (versión deleuzeana)», Yoel, Gerardo (comp.), Pensar el cine 1. Buenos Aires: Manantial 2004.

Saer, Juan José, Cicatrices, Buenos Aires: CEAL, 1983.

Sarlo, Beatriz, Zona Saer, Santiago de Chile: Universidad Diego Portales, 2016.

Terán, Oscar, Nuestros años sesentas, Buenos Aires: Siglo XXI, 2013.

Films de Leonardo Favio

Crónica de un niño solo, 1965

El romance del Aniceto y la Francisca, 1967

El Dependiente, 1968, estrenada los primeros días de 1969.

\section{Retrospectiva de Roberto Aizenberg}

Aizenberg: obras 1947/1968. Exh. cat., Buenos Aires: Centro de Artes Visuales del Instituto Torcuato Di Tella, 1969. En línea: icaadocs.mfah.org/icaadocs/ELARCHIVO/.../tabid/99/.../Default.aspx. Consulta: $08 / 06 / 2016$.

\section{NOTAS}

1. El deseo nace del derrumbe. Roberto Jacoby: acciones, conceptos, escritos es un texto fundamental para la recuperación de la historia del Di Tella y la actuación de Jacoby.

2. «[Ninguna de las artes...]», Aizenberg: obras 1947/1968. Exh. cat., Buenos Aires: Centro de Artes Visuales del Instituto Torcuato Di Tella, 1969. En línea: icaadocs.mfah.org/icaadocs/ ELARCHIVO/.../tabid/99/.../Default.aspx. Consulta 08/06/2016.

3. Es lo que Beatriz Sarlo a propósito de toda la obra de Saer llama «una sociedad de personajes», la gran saga que la crítica reconstruye, reponiendo fechas, enlazando relaciones y parentescos, rellenando las elipsis y marcando las prolepsis (2016: 79-99).

4. El trabajo de María del Carmen Rodríguez desarrolla estas ideas sobre el cine en Deleuze (2004: 91-126). 


\section{RESÚMENES}

En este trabajo analizo la retrospectiva de la obra de Roberto Aizenberg en el Instituto Di Tella realizada en 1969, la novela de Juan José Saer, Cicatrices y el film El dependiente dirigido por Leonardo Favio. Planteo cómo en estas obras aparece una estética o poética cuyos ejes trabajan sobre el vaciamiento del mundo, la repetición insistente de motivos, escenas, descripciones y la circularidad asfixiante de un relato que no avanza. En el contexto final de una época prolífica en expresiones artísticas, al borde de los 70, interrogo lenguajes que mantienen una relación alejada de los movimientos locales pero que se nutren de experiencias vanguardistas que provienen de Europa. Frente a la explosión de una extensa variedad de manifestaciones artísticas pero también en un período de complejidad política que culmina con el Cordobazo, estas obras manifiestan un repliegue y un desmontaje de los materiales con los que trabajan: palabras, voces, imágenes, espacio, tiempo.

The present paper analyzes the Roberto Aizanberg's work realized at the Di Tella Institute in 1969, Juan José Saer's Cicatrices and the film El dependiente directed by Leonardo Favio. My approach seeks to observe in these works a poetics or aesthetic focused of the emptiness of the world. The insistent repetition of scenes, motifs, descriptions accompanies an oppressive, circular relation that does not move forward. In the context of a fruitful epoch in terms of artistic expressions, on the verge of the seventies, I inquire the languages that keep a distant relation with local movements and nurture themselves of the avantgardist experiences in Europe. Before the explosion of a wide range of artistic manifestations, as well as a complex political moment that culminates with the Cordobazo, these works reveal the folding and dismounting of the materials with which they work: words, image, space, time.

Cet article analyse la rétrospective de 1969 de l'œuvre de Roberto Aizenberg à l'Instituto Di Tella de Buenos Aires, le roman Cicatrices de Juan José Saer et le film de Leonardo Favio El dependiente. J'essaie d'appréhender dans ces œuvres l'émergence d'une esthétique ou d'une poétique dont ses axes sont le vide du monde, la répétition permanente de motifs, l'étouffante circularité d'un récit qui n'avance pas. Dans le contexte final d'une époque prolifique en expressions artistiques, très près des années 1970, j'interroge les langages qui tout en gardant une relation éloignée des mouvements locaux, ils reprennent des expériences de l'avant-garde européenne. Face à l'explosion d'une vaste variété de manifestations artistiques mais aussi dans un période d'un complexité politique qui aboutit au Cordobazo, ces œuvres mettent en évidence un retrait et un démontage des matériaux avec lesquels elles travaillent: les mots, les images, l'espace, le temps.

\section{ÍNDICE}

Mots-clés: Aizenberg, Saer, Favio, vide, répétition.

Keywords: emptiness, repetition

Palabras claves: vaciamiento, repetición 
AUTOR

ISABEL A. QUINTANA

CONICET -ILH- UBA

isaaquintana@gmail.com 